\title{
Uber fossile Böden im nichtvereisten Gebiet
}

(Mitteilungen aus dem Hessischen Landesamt für Bodenforschung, Wiesbaden) von ERNST SCHÖNHALS, Wiesbaden

Mit 7 Abbildungen

I. Einleitung

In h a l t

II. Beobachtungen an fossilen Böcien

1. Rhein-Maingebiet

2. Niederhessische Senke

3. Böhmen und Mähren

4. Weitere Vorkommen fossiler Böden

III. Boden und Klima während der jungpleistozänen Verwitterungszeiten

IV. Zusammenfassung

V. Schriftenverzeichnis

I. Ein leitung

Für die Gliederung des Pleistozäns spielen bekanntlich die Bildungen der wärmeren Zeitabschnitte wie Torf, Kieselgur, Mergel, Kalk und marine Sedimente eine besondere Rolle. Leider finden sich diese meist auch räumlich begrenzten Ablagerungen in dem eis $\mathrm{f} r$ e i e $\mathrm{n}$ Gebiet recht selten, so daß uns hier nur geringes Beobachtungsmaterial für die Charakterisierung jener wärmeren Epochen zur Verfügung steht.

Umso wertvoller sind daher die erhalten gebliebenen Verwit te r u ng sdecken, die auf den pleistozänen Ablagerungen in verschiedener Mächtigkeit und Ausbildung entstanden. Selbstverständlich verfielen auch diese vorzeitlichen Böden auf großen Flächen der Abtragung, so daß wir meist nur noch Verwitterungszeugnisse des jüngeren Pleistozäns finden und auch diese nur an solchen Stellen, wo günstige Erhaltungsbedingungen vorhanden waren. Eine der wichtigsten Voraussetzungen für die Überlieferung begrabener Böden war die baldige Bedeckung mit neuem Gesteinsmaterial, ohne daß bei diesem Vorgang der Boden selbst zerstört wurde. Diese Voraussetzung war in erster Linie dort gegeben, wo der leichte L ö $B$ s t a u b den Boden unter sich begrub und so vor Abtragung schützte. Die Lößgebiete sind daher zum Studium der fossilen Böden des Pleistozäns besonders geeignet. Der Wert der auf den Lößen erhaltenen Verwitterungsdecken für vergleichende regionale Untersuchungen wird noch dadurch erhöht, daß das Bodenmuttergestein praktisch überall das gleiche ist; wesentliche Faktoren der Bodenbildung, wie die petrographische und chemische Zusammensetzung des Ausgangsgesteins, seine Korngrößenzusammensetzung und Struktur sind infolgedessen als konstant anzusehen, so daß im jeweiligen Bodentyp im wesentlichen der Einfluß des Klim as und der Geländeg es talt ung zum Ausdruck kommt. Die Einwirkungen des Reliefs können jedoch in den meisten Fällen noch durch den Verlauf der alten Landoberfläche erfaßt werden, so daß der Charakter des Klimas aus dem Bodenprofil zu ersehen ist.

Eine weitere Voraussetzung für die bodenkundliche und klimatische Auswertung der Beobachtungen ist die Datierung der Verwitterungsdecken, weshalb eine stratigraphische Gliederung der Deckschichten durchgeführt werden muß.

Die Untersuchungen, über die im folgenden berichtet wird, wurden in dem engeren Rhein-Maingebiet, in der nördlichen hessischen Senke sowie in Böhmen und Mähren anläßlich der in diesen Gebieten ausgeführten Bodenkartierung vorgenommen. Sie betrafen zunächst die geologische Gliederung und Datierung der jeweiligen Schichten und außerdem die bodenkundlichen Eigenschaften der eingeschalteten Verwitterungsdecken. Wie bei der Untersuchung der rezenten 
Böden, so wurde auch bei den fossilen eine genaue Horizontbeschreibung vorgenommen und auf alle für die Erkennung der einzelnen Bodenformen wichtigen Eigenschaften geachtet.

Im Rahmen dieser Veröffentlichung ist jedoch nur eine kurze Erläuterung der wichtigsten Profile möglich; Einzelheiten über die Ausbildung der Schichten und Bodenprofile können daher nicht mitgeteilt werden.

Die Grundlage aller Erörterungen bildet das gesamte Pleistozänprofil, weshalb es auch als Ausgangspunkt der folgenden Betrachtungen dienen soll.

\section{B e o b a h t ung en a n fossilen Böden}

1. Rhein-Maingebiet (vgl. hierzu die Arbeiten von SCHÖNHALS 1950, 1951).

Wir wenden uns zunächst einigen Profilen aus dem Rheingau zu, jenem fruchtbaren Gebiet, das sich zwischen dem Südabhang des Taunus und dem Rhein erstreckt. An großen SW-NO streichenden Verwerfungen sind hier die Ablagerungen des Mittel- und Oberoligozäns und des Untermiozäns staffelförmig abgesunken, um südlich des Rheins zum rheinhessischen Plateau wieder anzusteigen. Durch diese schon alt angelegten Störungen wird das heutige Landschaftsbild in seinen Grundzügen bestimmt, das schließlich im Pleistozän durch die Bildung verschiedener Terrassen und die Anwehung des Lößes sein jetziges Aussehen erhalten hat.

Man kann im Rheingau neben den jungtertiären Stufen, die sich am Gebirgsrand nach Westen hin bis unterhalb Bingen verfolgen lassen, 3 pleistozäne Terrassengruppen unterscheiden. Einmal die nur noch in kleinen Resten erhaltene Hauptterrasse in 200-260 $\mathrm{m}$ ü. NN., dann die obere und mittlere Mittelterrasse in etwa $120-180 \mathrm{~m}$ ü. NN und schließlich die in $90-100 \mathrm{~m}$ ü. NN sich hinziehende unterste Stufe der Mittelterrasse (Talwegterrasse), auf der die wichtigsten Siedlungen entlang des Rheins liegen. Die Niederterrasse, etwa $85 \mathrm{~m}$ ü. NN gelegen, ist nur an wenigen Stellen ausgebildet, so z. B. auf dem Eltville gegenüberliegenden Rheinufer. Mit Ausnahme der Niederterrasse werden die höheren Terrassenflächen von $L$ ö $\beta$ bedeckt, besonders die Talwegterrasse. Die obere Mittelterrasse wird wie GERTH (1909) und MORDZIOL (1910) zwischen Schierstein und Höchst beobachteten, von ä $1 \mathrm{t}$ e r e $\mathrm{m}$ L ö $ß$ überlagert, der eine bis $1,5 \mathrm{~m}$ mächtige Verlehmungsdecke trägt, die sich durch ,eine typische Vegetations- oder Humusdecke mit stellenweise nicht selten vorkommenden, zu Kohle umgewandelten Pflanzenresten" auszeichnet. Mächtigkeit und Ausbildung dieser Verwitterungsdecke erinnerten MORDZIOL an den älteren Löß des Niederrheins und an das klassische Lößprofil von Achenheim bei Straßburg. In den von GERTH und MORDZIOL erwähnten Aufschlüssen ist der ältere Löß mit dem darauf erhaltenen Boden nicht mehr zu beobachten. Im Sommer 1947 fand ich jedoch in dem von Erbach nach Eichberg hinaufführenden Hohlweg älteren Löß mit einer etwa $1 \mathrm{~m}$ starken Verwitterungsdecke; die alte Landoberfläche liegt in dem ersten Aufschluß bei $\mathrm{km} \mathrm{0,7} \mathrm{ca.} \mathrm{122,5} \mathrm{m} \mathrm{ü.} \mathrm{NN,} \mathrm{beim} \mathrm{zweiten} \mathrm{Aufschluß} \mathrm{unmittelbar}$ hinter dem Landhaus Marienhöhe ca. 139,5 m ü. NN. Die Schichtenfolge im Hohlweg ist aus Abb. $1 \mathrm{zu}$ ersehen.

Wie die Engebnisse der Korngrößenanalyse zeigen, handelt es sich bei dem begrabenen Boden um $\mathrm{t}$ y $\mathrm{p}$ is $\mathrm{c}$ h en $\mathrm{L}$ ö $\beta$, dessen Verwitterungsdecke nach den Profilbeobachtungen und chemischen Untersuchungen als degradierte Schwarzerde bezeichnet werden muß. Unter dem etwa $60 \mathrm{~cm}$ mächtigen, kaffeebraunen, schwach humosen A-Horizont folgt mit allmählichem Übergang ein gleichmäßig brauner, feinsandiger bis kräftiger Lehm, der etwa $40 \mathrm{~cm}$ mächtig wird (B-Horizont). Der Gesamthumusgehalt im A-Horizont, wahrscheinlich nur noch ein Rest des ehemals vorhandenen, beträgt $0,65 \%$; bei dem stärker degradierten Profil 
bei $\mathrm{km} 0,7$ wurde er nur noch zu 0,3\% ermittelt. ${ }^{1}$ ) Der Kalkgehalt im A-Horizont beträgt 3,5\%, im braunen B-Horizont nur noch 2,2 \%. Die pH-Werte (in $\mathrm{KCl}$ gemessen) liegen im A-Horizont (3 Proben) alle bei 7,6, im B-Horizont bei 7,4. Stärkere Verlagerungen der Sesquioxyde haben nicht stattgefunden. Nur im B-Horizont ist eine schwache Anreicherung von $\mathrm{Al}_{2} \mathrm{O}_{3}$ festzustellen, bei dem stärker degradierten Profil auch von $\mathrm{Fe}_{2} \mathrm{O}_{3}$.

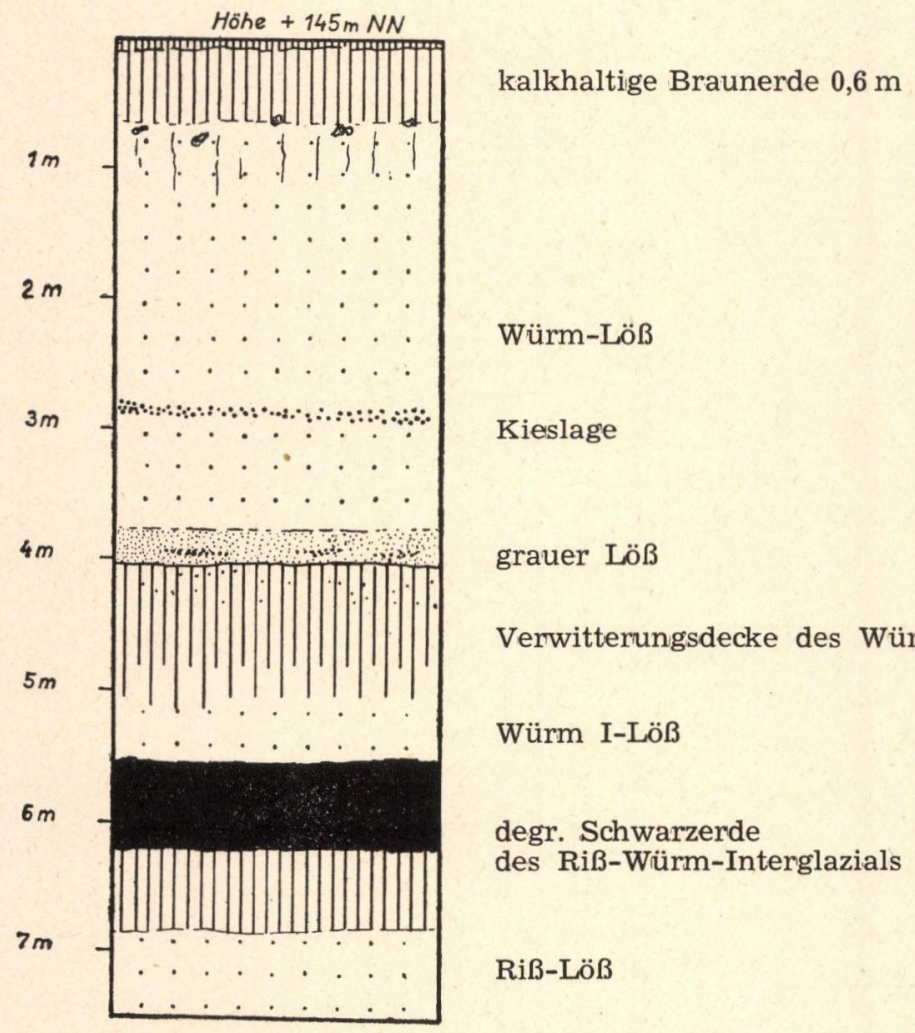

Abb. 1: Schichtenfolge und fossile Verwitterungsdecken am Landhaus Marienhöhe im Hohlweg von Erbach nach Eichberg.

Insgesamt kann aus den Untersuchungen auf eine geringe Durchfeuchtung während der Bildungszeit des Bodens geschlossen werden, so daß eine Anreicherung der Humusstoffe in dem an Basen gesättigten Boden stattfinden konnte. Da sich dieser fossile Boden in seinem Profilaufbau und Chemismus grundsätzlich nicht von den in unseren Steppengebieten der Nacheiszeit gebildeten und später degradierten Böden unterscheidet, kann diese fossile Verwitterungsdecke wohl als verbraunte oder degradierte $\mathrm{Sch}$ warzerde bezeichnet werden. Als Bildungszeit kommt die zwischen der Riß- und Würm-Vereisung gelegene Wärmezeit in Frage, die - wie unten noch dargelegt wird - auch in anderen Gebieten durch Schwarzerden charakterisiert ist.

Ein weiteres Schwarzerdevorkommen fand Herr Dr. PINKOW, Wiesbaden, unmittelbar nördlich von Geisenheim in einer Baugrube unter 4,5 m mächtigem

1) In einem älteren begrabenen Schwarzerdeprofil in Mähren fand PELIŠEK (1938) einen Humusgehalt von $0,4 \%$, in einer jüngeren fossilen Schwarzerde dagegen $1,8 \%$. 
jüngerem Löß. Die etwa $70 \mathrm{~cm}$ starke Schwarzerde wies keine auffälligen Degradationsmerkmale auf.

Während über dem fossilen Boden des Profils bei $\mathrm{km} \mathrm{0,7}$ zunächst ein 2,5 m mächtiger, mit Feinsand und Kies wechsellagernder Löß folgt, der ziemlich unvermittelt in reinen Löß übergeht, wird in dem Aufschluß unmittelbar hinter Marienhöhe der ältere Löß von einem ersten jüngeren Löß bedeckt, der $1 \mathrm{~m}$ tief verwittert ist. Er gliedert sich in einen $60 \mathrm{~cm}$ starken dunkelbraunen, noch kalkhaltigen Lehm und einen hellbraunen, kalkhaltigen, feinsandigen Lehm von $40 \mathrm{~cm}$; hierunter folgen noch $20 \mathrm{~cm}$ Löß. Bei dem gleichmäßig verteilten Kalkgehalt handelt es sich nicht um von oben zugeführten Kalk, sondern um den Rest des ehemals vorhandenen. Da die darunterliegende letztinterglaziale Schwarzerde unmittelbar nach ihrer Bildung zugedeckt wurde, dürfte der verlehmte Löß zu Beginn des Würm-Glazials abgelagert worden sein. Wäre die Überdeckung mit Löß nicht bald erfolgt, so würde die Schwarzerde sehr wahrscheinlich abgetragen oder stärker degradiert worden sein. Die Lagerungsverhältnisse sprechen daher für eine Eingruppierung des über der Schwarzerde liegenden Lößes in das

\section{Zgl. Klüter, Eltville}

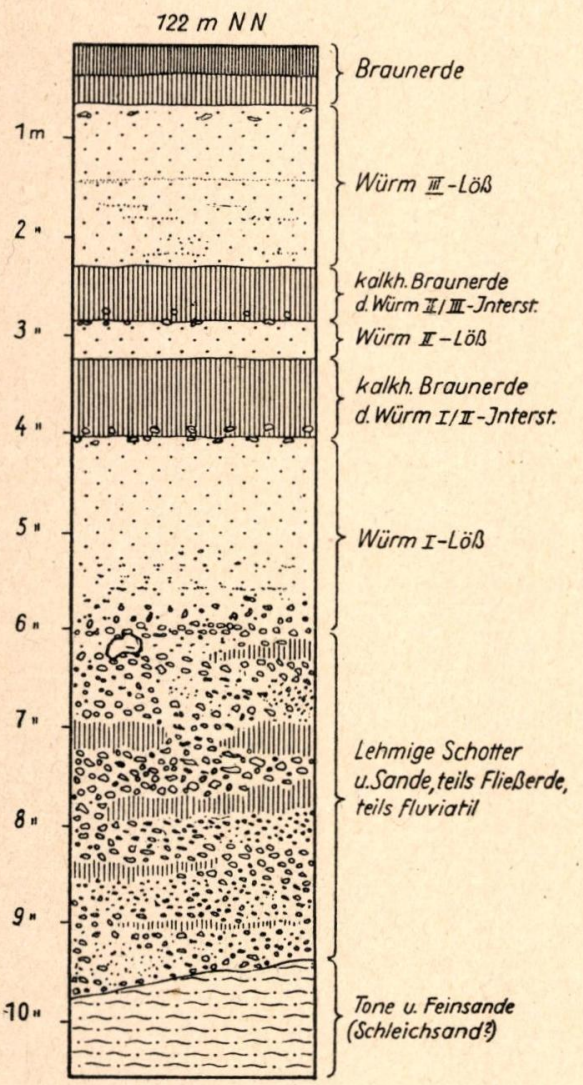

Abb. 2: Gliederung des Pleistozäns in der Ziegelei Klüter. (Das in 1,5 m Tiefe eingelagerte dunkle Band ist durch eine feine Punktierung angedeutet).
Würm I-Glazial; die Verlehmung wäre dann dem Würm I/II-Interstadial zuzuweisen. Bodentypologisch gehört die Verwitterungsdecke zu der Gruppe der Br a unerden, und zwar wegen des noch vorhandenen Kalkgehalts $\mathrm{zu}$ den noch nicht voll entwickelten.

Bei dem über der Verlehmungszone folgenden $45 \mathrm{~cm}$ starken, hellgrauen Mehlsand handelt es sich wahrscheinlich um verwehte feinkörnige Sande aus den ganz in der Nähe anstehenden Süßwasserschichten des Cyrenenmergels; die vereinzelt vorkommenden Feinkieseinlagerungen dürften auf das am Hang abfließende Niederschlagswasser zurückzuführen sein

Der 3,8 m mächtige hangende Löß wird etwa $3 \mathrm{~m}$ unter der Oberfläche durch ein $5-8 \mathrm{~cm}$ starkes Kiesband, das schwach nach $\mathrm{S}$ einfällt, zweigeteilt. Es markiert vermutlich eine Abtragungsfläche, so daß der heute als einheitlich erscheinende Lößkomplex unter Umständen 2 verschiedenaltrige Löße darstellt (Würm II und Würm III).

$\mathrm{Da}$ der jüngere Löß im Rheingau vielfach einen dreiteiligen Aufbau besitzt, zeigt $u$. a. das in Abb. 2 wiedergegebene Lößprofil.

In der ZiegeleiKlüter liegt auf der teilweise von Fließerden bedeckten oberen Stufe der unteren Mittelterrasse eine etwa $6 \mathrm{~m}$ mächtige Lößdecke, die bei nähe- 
rer Untersuchung eine Dreiteilung erkennen läßt. Der untere Löß von gelblichgrauer Farbe trägt eine $0,8 \mathrm{~m}$ mächtige, braune Verlehmungsdecke, die im gesamten Horizont zahlreiche nadelstichgroße, schwärzlichbraune Flecken aufweist. Der noch nachweisbare gleichmäßig verteilte Kalkgehalt und Schalenreste von Tertiärfossilien beweisen, daß keine vollständige Verlehmung stattgefunden hat. Auch die nur Walnußgröße erreichenden Lößkindel im untersten Teil der Verlehmungszone sprechen für eine weniger intensive Verwitterung. Der Lehm ist z. T. von leuchtend rostbraunen Flecken durchsetzt, besonders im unteren Teil, wo der Lehm auch eine etwas tonigere Beschaffenheit hat.

Über diesem ersten Würm-Löß mit seiner nicht restlos entkalkten Bodendecke lagert ein zweiter, geringmächtiger, der wiederum eine braune Verwitterungsdecke trägt. Sie ist nur $0,5 \mathrm{~m}$ mächtig, ebenfalls noch kalkhaltig und weist nur einzelne rostbraune Flecken auf. Daß auch hier eine Verwitterung an Ort und Stelle stattgefunden hat, geht aus den im unteren Teil der Verlehmungszone vorkommenden kleinen Lößkindeln und den Kalküberzügen im dazugehörigen Löß hervor.

Der dritte Würm-Löß wird etwas über $2 \mathrm{~m}$ mächtig; von besonderer Wichtigkeit ist ein in 1,5 m Tiefe eingelagertes, $2-3 \mathrm{~cm}$ starkes, dunkelgraues Band, das auch noch an anderen Stellen des Rheingaues gefunden wurde. Von der Ziegelei Klüter wird es bereits von MICHELS (1931) erwähnt und mit vulkanischer Asche in Verbindung gebracht.

Ähnliche dunkle Bänder kommen auch im Löß des Limburger Beckens vor, und zwar am Mensfelder Kopf (Bl. Limburg), in der Ziegelei Eufinger, Elz, nordwestlich von Limburg und im Kerkerbachtal auf Bl. Hadamar. (Diese Vorkommen lernte ich durch Herrn Prof. MICHELS anläßlich einer Fahrt durch das Limburger Becken Anfang Nov. 1950 kennen).

W. HESS (1909) erwähnt schon das $2-3 \mathrm{~cm}$ starke dunkle Bändchen aus dem Löß des Limburger Beckens und teilt mit, daß es sich nach einer Untersuchung von Prof. Dr. BRUHNS um vulkanisches Material handelt, das im wesentlichen aus Sanidin und Augit besteht. Von mir veranlaßte und noch nicht abgeschlossene mineralogische Untersuchungen an Material aus dem Rheingau (durch Herrn Dr. von STEINWEHR vom Inst. für Mineralogie und Petrographie der Universität Mainz, Direktor: Prof. Dr. BAIER) und aus dem Limburger Becken (durch Herrn Dr. habil. HENTSCHEL vom Landesamt für Bodenforschung, Wiesbaden) konnten bisher keine Beweise für eine vulkanische Entstehung erbringen. ${ }^{2}$ ) Doch ist eine andere Entstehung kaum möglich, da die im Material des Limburger Beckens zahlreich vorhandenen Augite auf eine andere Weise wohl nicht erklärt werden können. Die ziemlich gleichmäßige Verteilung der Augite in dem dünnen Schichtchen innerhalb des kalkhaltigen Lößes deutet darauf hin, daß der Löß und das dunkle Material gleichzeitig angeweht wurden. Nähere Untersuchungen an allen bekannt gewordenen Vorkommen geben vielleicht Aufschluß über Natur und Herkunft der dunklen Einlagerung, die insofern eine besondere Bedeutung erlangt, als sie einen sicheren Leith orizon $t$ für den jüngsten Würm-Löß darstellt, denn das Bändchen liegt in der Ziegelei Klüter über den beiden Verlehmungszonen des Würm I/II- und des Würm II/III-Interstadials.

Nicht weit von diesem Aufschluß entfernt konnte in der Albus-Hohl ein zweites Mal die Dreigliedrigkeit des jüngeren Lößes nachgewiesen werden. Auch hier lagert der Würm I-Löß auf der unteren Mittelterrasse. Die etwa $40 \mathrm{~cm}$ starke

2) Den genannten Herren sei für ihre bereitwillige Mitarbeit auch an dieser Stelle herzlich gedankt. 
Verwitterungsdecke ist zusammen mit dem Löß der Abtragung teilweise zum Opfer gefallen. Es folgt über der die Erosionsfiäche bedeckenden Fließerde der 0,5 bis $1 \mathrm{~m}$ mächtige Würm II-Löß, ebenfalls mit einer Verwitterungsdecke von etwa $0,5 \mathrm{~m}$. Der braune Lehm besitzt noch einen schwachen primären Karbonatgehalt und außerdem von oben zugeführten Kalk in Form von Pseudomyzel. Die an der Basis der Verlehmungszonen und in den liegenden Lößen vorkommenden Lößkindel beweisen, daß es sich um echte Verwitterungsbildungen vom Typ der Braunerde und nicht etwa um umgelagerten Lößlehm handelt. Der $3 \mathrm{~m}$ mächtige Würm III-Löß wird durch das für den Rheingau typische Braunerdeprofil abgeschlossen.

Weitere würminterstadiale Verwitterungsdeckeni wurden in der näheren Umgebung von Wiesbaden beobachtet, so in der Ziegelei bei der Wahlmühle (Straßenkreuzung Wiesbaden-Schierstein und Dotzheim-Biebrich) und in den beiden Ziegeleien an der Straße Wiesbaden-Erbenheim. Mächtigkeit und Ausbildung zeigen nur geringe Unterschiede. Die Verlehmungszonen sind nicht stärker als $0,7 \mathrm{~m}$, von hell- bis dunkelbrauner Farbe und zuweilen mit rostfarbigen Eisenhydroxydflecken. Der primäre Kalkgehalt ist meist noch nachzuweisen. Verdichtungen oder Verlagerungen von Eisen-Humus-Solen, die auf eine geringere Basensättigung oder Podsolierung hinweisen würden, wurden nicht beobachtet. Die erhaltenen Böden können daher ebenfalls den Braunerden zugewiesen werden.

Auch aus den ausgedehnten Lößgebieten des Vorta u n u s und der We tt e $\mathrm{r}$ a $\mathrm{u}$ sind fossile Verwitterungsdecken bekannt geworden, und zwar über $3 \mathrm{~m}$ mächtige humose Verlehmungszonen auf älterem Löß (Sossenheim, Münzenberg) und bis etwa $1 \mathrm{~m}$ starke braune Verlehmungsdecken im jüngeren Löß. Bisher konnten in diesen Gebieten nur einzelne Profile flüchtig besichtigt werden; nähere Untersuchungen sollen noch durchgeführt werden.

Das Profil von Münzenberg in der Wetterau wurde bereits 1910 von HARRASSOWITZ beschrieben und später chemisch untersucht. Der unter dem 3,5 m mächtigen, $1 \mathrm{~m}$ tief verlehmten jüngeren Löß begrabene Boden gliedert sich nach HARRASSOWITZ (1930, S. 262) wie folgt:

1. Humusreicher Lehm, Schwarzerde

2. Grauerde

$1-1,5 \mathrm{~m}$

$0,5 \mathrm{~m}$

3. Älterer Lehm mit vereinzelten Geröllen, oben stärker gebräunt $2,5 \mathrm{~m}$

4. Älterer Löß, dunkelgelb, ungeschichtet, mit großen Lößkindeln $3,0 \mathrm{~m}$

Die Horizonte 1 und 2 sind vollkommen frei von Kalziumkarbonat und weitgehend an Basen verarmt; den stärksten Verlust an Basen hat die "Grauerde“ erlitten, die „einen ausgesprochen sandigen Eindruck macht." Nach den Untersuchungen von HARRASSOWITZ möchte ich annehmen, daß es sich ursprünglich um eine Schwarzerde handelte, die später nach einer Klimaverschlechterung unter der Einwirkung einer Waldvegetation stark degradiert bzw. podso1 i e r t wurde.

Eine sichere A ltersfestlegung dieses Profils kann nicht erfolgen; doch spricht die tiefreichende und intensive Verwitterung für eine lang andauernde Wärmezeit mit Klimaschwankungen, d. h. für ein Interglazial. Obgleich die stark degradierte Schwarzerde in der unmittelbaren Nachbarschaft z. T. abgetragen wurde, muß die Bedeckung mit jüngerem Löß bald erfolgt sein, so daß mit groß̉er Wahrscheinlichkeit als Bildungszeit das letzte Interglazial (Riß-Würm) angesehen werden kann.

Einen ähnlichen morphologischen Aufbau besitzt das unter jüngerem Löß erhaltene Bodenprofil in der Lehmgrube am Südausgang von Berstadt $(7 \mathrm{~km}$ in südöstlicher Richtung gelegen). Der $A_{1}-$ Horizont ist etwa $70 \mathrm{~cm}$, der graubraune 
A2-Horizont $30 \mathrm{~cm}$ und der rötlichbraune B-Horizont $60 \mathrm{~cm}$ mächtig. (Ủber die noch nicht abgeschlossenen Feld- und Laboratoriumsuntersuchungen dieses Profils wird später berichtet werden).

Ganz andere Bodentypen wie die bisher aus dem Rheingau und der Wetterau besprochenen kommen im Usinger Becken, also am NO-Ende des Taunus vor. Hier sind in der Ziegelei Jack, Usingen, auf den beiden unteren verlagerten Lößlehmen 2 extrem gleiartige Böden erhalten, während auf dem jüngsten Lößlehm eine B r a u n e r d e entwickelt ist. Da sich das Ausgangsmaterial bei allen 3 Lößlehmen nicht unterscheidet und außerdem die Hangneigung der beiden vorzeitlichen Landoberflächen die gleiche war wie die der rezenten, kann der vertikale Bodentypenwechsel nur klimatisch bedingt sein, und zwar deuten die beiden fossilen, extrem gleiartigen Böden im Gegensatz zu der rezenten Braunerde auf zwei feuchtere und kühlere Klimaphasen hin.

Der gleiche Bodentypenwechsel ist auch an mehreren Stellen am Südwestund Nordostrand des Vogelsbergs zu beobachten. In allen Fällen kommt auf Grund der geologischen Lagerungsverhältnisse für die eingeschalteten Verwitterungsdecken ein w ü rmeis zeit 1 i c hes Alter in Betracht. Weitere Einzelheiten können in diesem Zusammenhang nicht mitgeteilt werden, weshalb auf die entsprechende Arbeit verwiesen wird (SCHÖNHALS 1951).

Auch in $\mathrm{R} h$ ei $\mathrm{n}$ hess e $\mathrm{n}$ sind in den meist mächtigen Lößdecken alte Böden erhalten geblieben; so wurde bereits 1917 von HOHENSTEIN (1920) in der Ziegelei SCHNELL am Bahnhof Sprendlingen (Bahnstrecke Alzey-Bingen) eine begrabene $\mathrm{kalkhaltige} \mathrm{Schwarzerde}$ gefunden und beschrieben; später erfolgte durch SCHNELL (1928) eine eingehende chemische Untersuchung des gesamten Lößprofils. Eine Degradation der Schwarzerde konnte nicht festgestellt werden; nach den Angaben von HOHENSTEIN wird „der obere begrabene Schwarzerdehorizont" $0,3-1,75 \mathrm{~m}$ mächtig. Unter dieser Schwarzerde folgt zunächst der dazugehörige Löß von $0,3-1,0$ m Mächtigkeit und dann ein „unterer begrabener Schwarzerdehorizont", der 0,5-0,6 m mächtig wird und sich an einer tieferen Stelle der Grube mit dem oberen Schwarzerdehorizont vereinigt. Vermutlich ist dieses Ineinanderlaufen der beiden Schwarzerdehorizonte durch eine Erosionsdiskordanz bedingt.

Zwei weitere begrabene Böden sah ich im April 1949 anläßlich der Exkursion der Geologischen Vereinigung in der Nähe von Alzey. Dort war auf dem tiefsten Löß ein Bodenprofil erhalten, das nach Meinung aller anwesenden Bodenkundler als degradierte Schwarzerde bezeichnet werden muß (Krotowinen). Hierüber folgt ein umgelagerter Löß mit einem zweiten fossilen Bodenprofil, dessen typologischer Charakter noch nicht eindeutig bestimmt werden konnte (degradierte Schwarzerde oder Braunerde). Ein zweiter jüngerer Löß schließt das Profil ab.

Über die Datierung dieser begrabenen Böden und ihren speziellen Profilaufbau kann erst nach Durchführung weiterer Untersuchungen Näheres ausgesagt werden.

\section{Niederhessische Senke}

Bereits im Jahre 1934 fand ich in der Lehmgrube am Friedhof von Holzhausen bei Homberg a. d. Efze unter einem 1,3 m mächtigen, verlehmten jüngeren $L$ ö $B$ und einer $0,6 \mathrm{~m}$ mächtigen F li e $B$ e r d e einen Boden, der eine deutliche Horizontgliederung aufwies (SCHÖNHALS 1945). Der 0,5 m starke, schwarzbraune, humose A-Horizont geht allmählich in einen leicht zerreiblichen, hellgrauen Feinsand von $0,4 \mathrm{~m}$ über. Unter diesem durch Farbe, Bodenart und Struktur als Auswaschungszone $\left(\mathrm{A}_{2}\right)$ gekennzeichneten Horizont folgt der 2,5 $\mathrm{m}$ starke dunkelbraune Anreicherungshorizont mit auffallender Marmorierung und zahlreichen 
kleinen schwärzlichen Konkretionen. Der liegende ältere Löß, 1,4 m mächtig, ist noch kalkhaltig und enthält zahlreiche kleine Lößkindel. Dieser stark podsolierte Boden mit Anzeichen von Staunässe wurde einer würminterstadialen Verwitterungsphase zugewiesen, wobei noch bemerkt werden muß, daß die tiefreichende Verwitterung von über $3 \mathrm{~m}$ im wesentlichen durch die Tallage bedingt ist, denn eine bedeutend schwächere und andersartige Verwitterung lassen demgegenüber die interstadialen Verwitterungsdecken im jüngeren Löß der Gegend Fritzlar-Gudensberg erkennen, die ich im Herbst 1946 untersuchte.

Zunächst sei darauf hingewiesen, daß der jüngere Löß in dem nördlich der breiten Ederniederung gelegenen Gebiet erheblich größere Mächtigkeiten erreicht als in der Umgebung von Homberg. Die bis über $6 \mathrm{~m}$ anschwellende Lößdecke wird nach den bisherigen Beobachtungen nur von e i $\mathrm{n}$ e $\mathrm{m}$ fossilen Boden in einen jüngeren Löß 1 und jüngeren Löß 2 gegliedert. Da jedoch in fast allen Aufschlüssen das Liegende des Lößes nicht ansteht, ist es nicht ausgeschlossen, daß auch noch ein tieferer, der Beobachtung zur Zeit nicht zugänglicher Löß mit seiner Verwitterungsdecke existiert. Die interstadialen Verlehmungszonen, die ich bei Kirchberg, Lohne, Wehren-Nord (Blatt Fritzlar) und Gudensberg auf dem gleichnamigen Blatt beobachten konnte, werden $0,3-0,8 \mathrm{~m}$ mächtig; sie haben meist eine hellbraune Farbe und sind alle noch kalkhaltig. Der Gehalt an kohlensaurem Kalk unterscheidet sich nur wenig von dem des Lößes. Während dieser $10-17 \% \quad \mathrm{CaCO}_{3}$ aufweist, liegen die Kalkgehalte bei den Verlehmungszonen zwischen 10 und $13 \%$.

Auch im nördlichen Eichsfeld hatte der bei Bilshausen von SELZER (1936) beobachtete Verlehmungshorizont eine ähnliche Mächtigkeit $(0,4 \mathrm{~m})$.

\section{Böhmen und $M$ äh ren}

Diese beiden für den Quartärgeologen und Urgeschichtler überaus interessanten Gebiete bergen in ihren ausgedehnten und mächtigen Lößdecken an zahlreichen Orten begrabene Böden, deren Untersuchung $\mathrm{zu}$ wichtigen Ergebnissen führte. Während wir in den bisher erläuterten Profilen die Verwitterungsdecken des Riß-Würm-Interglazials und der beiden Würm-Interstadiale an ein und derselben Stelle nicht übereinanderliegend fanden, konnte diese normale Lagerung im böhmisch-mährischen Raum beobachtet werden ${ }^{3}$ ). In der vorliegenden Arbeit können nur die stratigraphisch und paläopedologisch wichtigsten Profile abgebildet und erläutert werden.

Betrachten wir zunächst 3 Profile aus der Umgebung von P rag und K ö n i gg rätz (Abb. 3, 4 und 5). Nach den Untersuchungen von ZARUBA-PFEFFERMANN $(1942,1943)$ werden die Schotterdecken der Weinberger (Mindel I) und Dewitzer (Prä-Riß) Terrasse in den Seltzer Ziegeleien (Abb. 3) von über $10 \mathrm{~m}$ mächtigen Lößen überlagert. Insgesamt konnten 6 Löße unterschieden werden; die 3 älteren, nach ZARUBA-PFEFFERMANN der R i B-Eiszeit zugehörig, werden jeweils von degradierten $\mathrm{Sch}$ w a rzerden abgeschlossen, während die $3 \mathrm{~W}$ ü r m - L öße durch 2 etwa $0,4 \mathrm{~m}$ starke b r a un e Ver w i t t e r ung s$\mathrm{z}$ on e $\mathrm{n}$ und mitunter durch Fließerden unterbrochen sind, die auch in weiteren Aufschlüssen bei Prag vorkommen. Die braunen Verwitterungsdecken im jüngeren Löß werden von ZARUBA-PFEFFERMANN als Reste alter Braunerden angesehen. Zahlreiche bis $1,8 \mathrm{~m}$ lange und $0,4-0,7 \mathrm{~m}$ breite Eiskeile, die mit

3) Die Ergebnisse meiner Untersuchungen waren in der Arbeit „Urber die Stratigraphie der jüngeren Diluvialablagerungen Nord- und Mittelböhmens und ihre fossilen Verwitterungsdecken" niedergelegt und im Druck. Durch die Kriegsverhältnisse konnte die Abhandlung jedoch nicht erscheinen. 


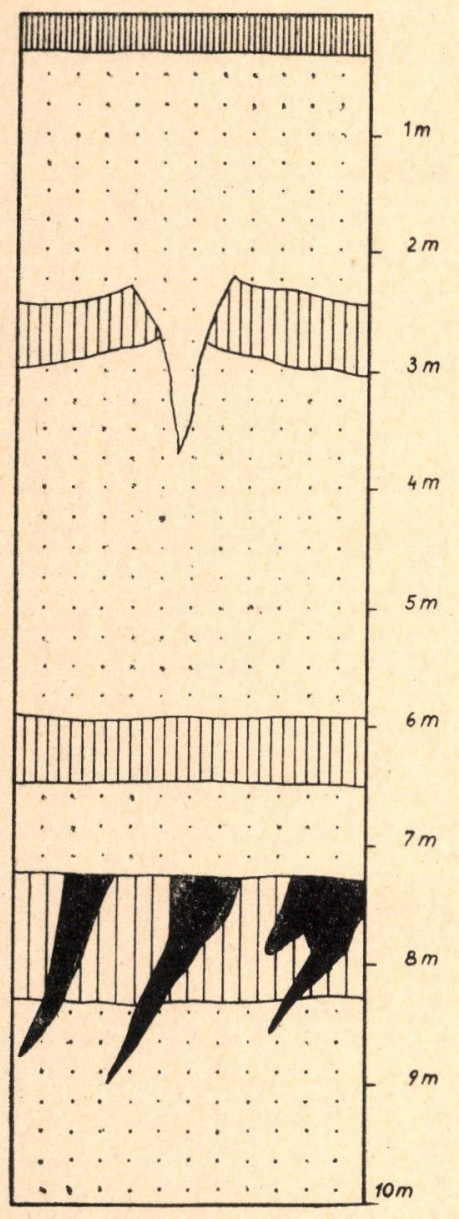

Braunerde
Würm III-Löß
Braunerde d. Würm II/III-Interstadials
von einem Eiskeil d. Würm III durchschnitten

Würm II-Löß

Braunerde d. Würm I/II-Interstadials

Würm I-Löß

abgetragene, degradierte Schwarzerde d. RißWürm-Interglazials; Eiskeile mit Schwarzerde gefüllt.

Riß III-Löß

Abb. 3: Gliederung des Pleistozäns in der Ziegelei Seltz bei Prag. Ausschnitt aus einer Zeichnung von ZARUBA-PFEFFERMANN (1943).

Schwarzerde oder Löß gefüllt sind, durchschneiden die begrabenen Böden, besonders die Bodendecken des Riß II- und des Riß III-Lößes.

Ähnliche Deckschichtenprofile konnten in der Umgebung von Königgrätz beobachtet werden. In der Ziegelei Komarek bei Freihöfen (Abb. 4) wird die jüngste Riß-Terrasse der Elbe von einem etwa $60 \mathrm{~cm}$ mächtigen feinsandigen Lehm von schwärzlichbrauner Farbe bedeckt. Der stark humose, milde Lehm besitzt eine feinplattige Struktur und ist vollkommen entkalkt. Alle Eigenschaften weisen also auf eine schwach degradierte Schwarzerde hin; Grundwassereinflüisse sind nicht zu erkennen. Über dieser im Riß-Würm-Interglazial gebildeten Verwitterungsdecke folgt ein $7 \mathrm{~m}$ mächtiger Lößkomplex, der durch 2 Verlehmungszonen in 3 Lößdecken unterteilt werden kann. Das würmeiszeitliche Alter der über der Schwarzerde liegenden Lößdecken wird durch Aurignacien-Funde bestätigt, die sich im Museum von Königgrätz befinden (SNAJDR 1909).

Die beiden entkalkten interstadialen Verwitterungsdecken, 1,8 und 1,2 m mächtig, haben hell- bis dunkelbraune Farbe und säulig-vieleckige Struktur; sie 
gehören somit zu den Braunerden mit tiefreichender Verlehmung. Der geringe Kalkgehalt in Form von Pseudomyzel und Utberzügen stammt aus dem hangenden Löß.

Einen vortrefflichen Einblick in den Aufbau der pleistozänen Hochfläche vermittelt eine fast $10 \mathrm{~m}$ tiefe Ausschachtung westlich Plotischt (Abb. 5). Hier liegen die Schotter und Kiese der jüngsten Riß-Terrasse $8,5 \mathrm{~m}$ unter der Oberfläche $(239,5 \mathrm{~m}$ ü. NN). Der darüber folgende $1,5 \mathrm{~m}$ mächtige Lehm dürfte als umgelagerter Lößlehm zu deuten sein (Fließerde). Auf diesem auch jetzt noch schwach kalkhaltigen Material entstand im Riß-Würm-Interglazial eine Schwarzerde, die fast vollständig entkalkt ist und in zahlreichen Eiskeilen steckt; diese entstanden während der folgenden kälteren Phase, in welcher auch der tiefste Würm-Löß angeweht wurde. Die Verwitterungsdecke des Würm I-Lößes ist 1,2 m mächtig, von brauner Farbe und nur noch schwach kalkhaltig $(1,3 \%)$. Der dazugehörige liegende Löß hat demgegenüber einen Kalkgehalt von 9,5\%. Im höheren 4,4 m mächtigen Löß nimmt der Kalkgehalt zu; so beträgt er im unteren Teil $11,2 \%$ und noch weiter oben $16 \%$. Eine zweite interstadiale Verwitterungsdecke, die in einem benachbarten Aufschluß zu beobachten war, ist hier nicht vorhanden, so $\mathrm{da} B$ an dieser Stelle mit ihrer Abtragung gerechnet werden muß.

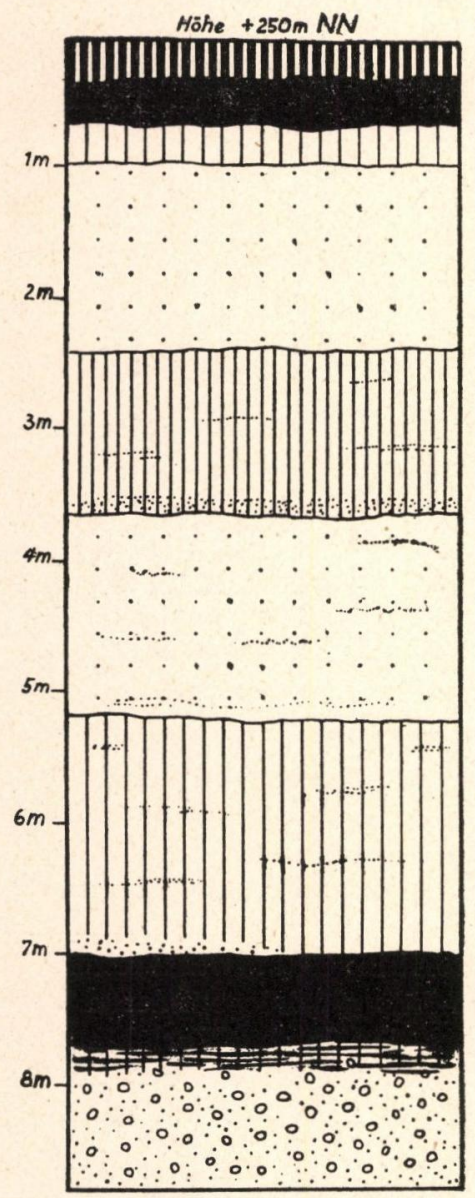

degradierte Schwarzerde mit $\mathrm{A}_{1-}, \mathrm{A}_{2}-$ und B-Horizont

Würm III-Löß

Braunerde d. Würm II/III-Interstadials

Würm II-Löß

Würm I-Löß, im Würm I/II-Interstadial verlehmt (Braunerde)

degradierte Schwarzerde d. Riß-WürmInterglazials

jüngste Riß-Terrasse $242,5 \mathrm{~m}$ ü. $\mathrm{NN}$

Abb. 4: Schichtenfolge und fossile Böden in der Ziegelei Komarek. 
Während wir in den bisher besprochenen Profilen Schwarzerden und Braunerden kennengelernt haben, begegnen wir in den folgenden Aufschlüssen auch $\mathrm{P}$ ods ol profilen, die die beiden Würm-Interstadiale in dem 70 bis $80 \mathrm{~km}$ weiter westlich gelegenen Gebiet um Böhmisch-Brod und Jungbunzlau charakterisieren.

In der Ziegelei Klima südwestlich Böhmisch-Brod können insgesamt 4 Löße unterschieden werden. Sehr wahrscheinlich gehört der unterste, der sich durch eine wesentlich stärkere Verlehmung von den jüngeren Lößen unterscheidet, zur vorletzten Eiszeit. Die Lößbildung im Würm I begann zunächst mit einer Anwehung von Flugsand, der fein geschichtet ist und der Neigung der Oberfläche entsprechend nach $\mathrm{N}$ einfällt. Der Flugsand geht ziemlich unvermittelt in hell-

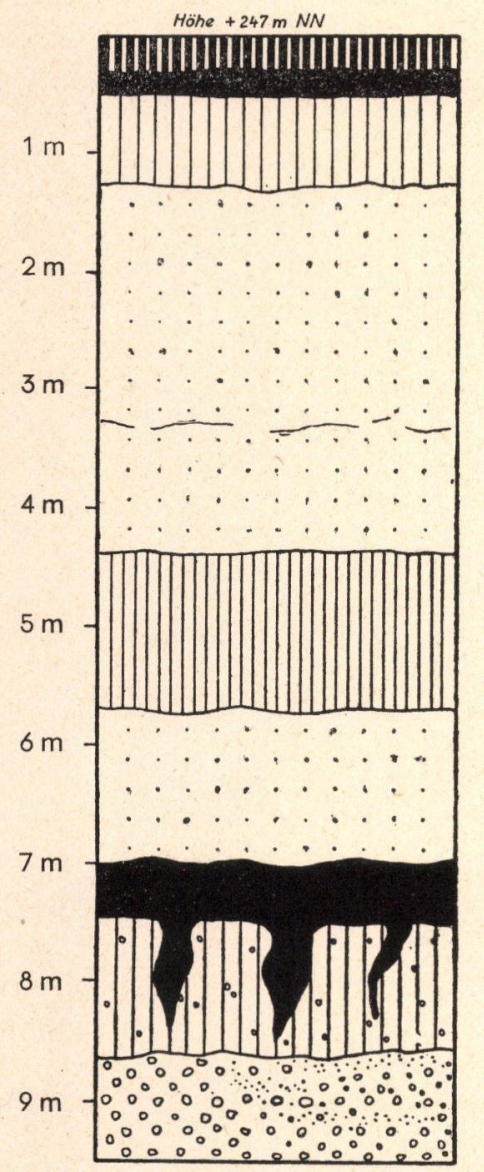

degradierte Schwarzerde mit $\mathrm{A}_{1-}, \mathrm{A}_{2}-$ und

B-Horizont

Würm-Löß (III ?)

Würm-Löß (II ?)

Braunerde d. Würm I/II-Interstadials

Würm I-Löß

degradierte Schwarzerde d. Riß-Würm-Interglazials; Eiskeile mit Schwarzerde gefüllt

jüngste Riß-Terrasse, $239,5 \mathrm{~m}$ ü. NN

Abb. 5: Schichtenfolge und fossile Böden an der Baustelle westlich Plotischt.

gelben Löß über, dessen im Würm I/II-Interstadial entstandene Verwitterungsdecke noch vollkommen erhalten ist. Es handelt sich um ein ausgeprägtes Podsolprofil mit A1-, $\mathrm{A}_{2}-$ und B-Horizont, das den später noch zu besprechenden Profilen ähnelt. Unter dem $30 \mathrm{~cm}$ starken dunkelgraubraunen Lößlehm des A1-Horizontes folgt ein $40 \mathrm{~cm}$ starker hellgrauer, stark feinsandiger Auswaschungshorizont und unter diesem der braune, $1 \mathrm{~m}$ mächtige Einwaschungshorizont mit Verdichtungen und schaligen Eisenhydroxyd-Verkittungen. 


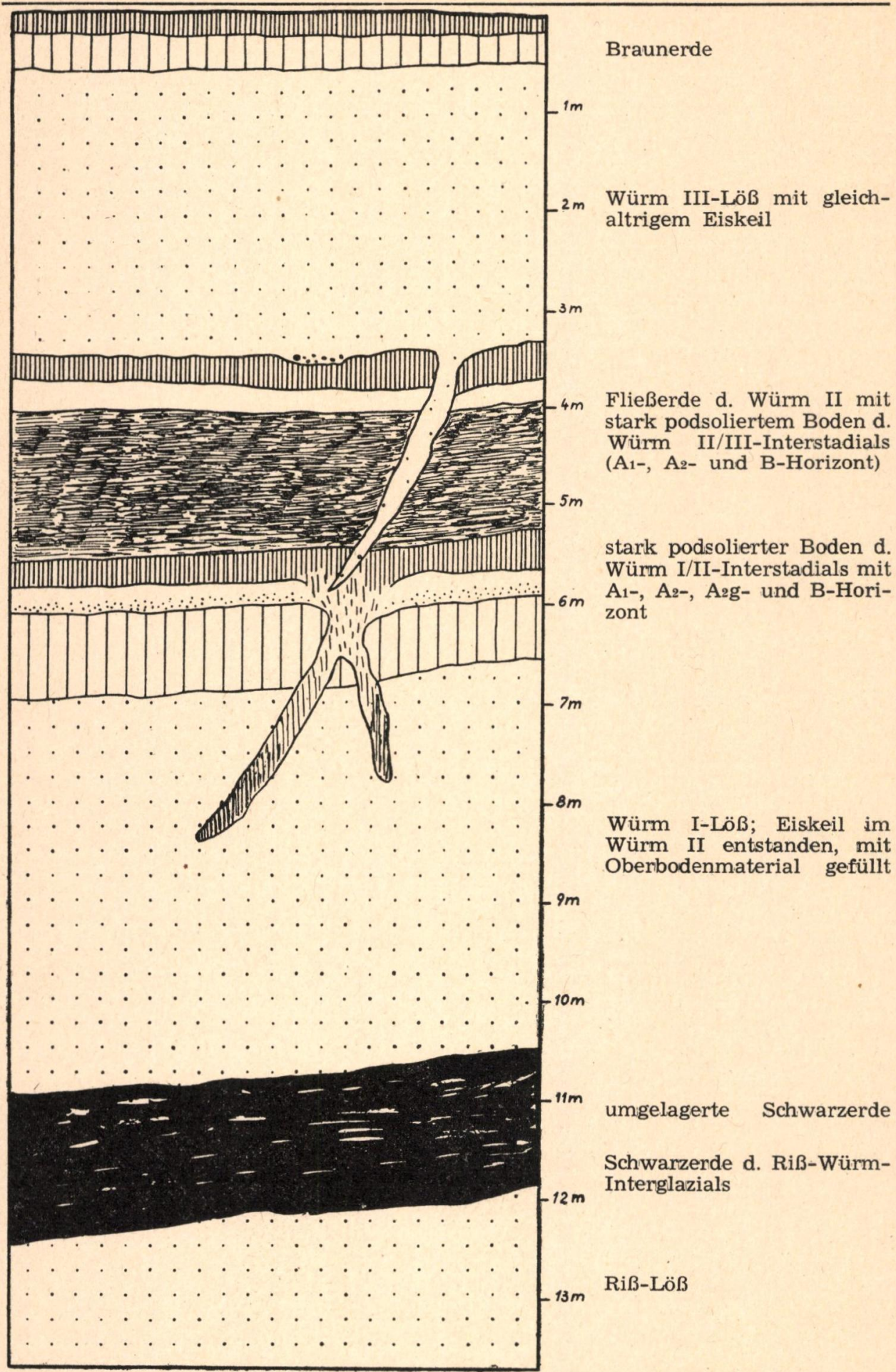

Abb. 6: Das Pleistozän und die fossilen Böden in der Ziegelei Hegel, Horka a. d. Iser. 
Das Podsolprofil wird von Eiskeilen durchschnitten, die bis in den kalkhal-

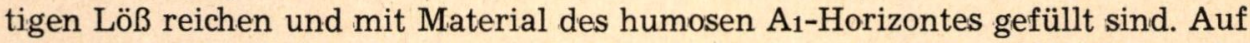
dieser von Frostkeilen durchzogenen Oberfläche kam der Würm II-Löß zur Ablagerung, der jedoch in dem nächsten Interstadial vollständig verlehmte $(1,3 \mathrm{~m})$. Die größte Mächtigkeit erlangt der Würm III-Löß mit einem rezenten Verlehmungshorfzont von $0,6 \mathrm{~m}$ (verbraunte Schwarzerde).

Ein noch vollständigeres Bild des Jungpleistozäns und seiner Verwitterungsdecken bietet die Abbauwand der Ziegelei J. Hegel in Horka a. d. Iser, südlich von Jungbunzlau (Abb. 6). Auf dem tiefsten Löß ist hier wiederum eine Schwarzerde entwickelt, von der jedoch nur der obere, $0,8 \mathrm{~m}$ starke, schwach umgelagerte Teil beobachtet werden konnte (Schwarzerde mit Lößschmitzen). Den Mitteilungen des Ziegeleibesitzers und einer Photographie, die auch die früher aufgeschlossenen tieferen Schichten erkennen ließ, war jedoch zu entnehmen, daß die Schwarzerde noch tiefer reicht und einen älteren Löß bedeckt. Nach $\mathrm{N}$ hin fehlt die Schwarzerde infolge Abtragung, so daß der Würm I-Löß ohne die letztinterglaziale Verwitterungsdecke auf älterem Löß liegt. Die Schwarzerde dürfte wie in der Ziegelei Komarek und an der Baustelle westlich Plotischt im Riß-WürmInterglazial entstañden sein. Diese Altersbestimmung wird durch die in dem Würm I-Löß und in der Fließerde ausgebildeten Frostspalten gestützt, denn jede Frostspalte entspricht einer Kaltzeit, so daß sowohl durch die 3 selbständigen Ablagerungen (Löß-Fließerde-Löß) als auch durch die verschiedenaltrigen Frostspalten und die beiden gleichgearteten Verwitterungszonen auf $3 \mathrm{~K}$ a l $\mathrm{t} z$ e i t e $\mathrm{n}$ $\mathrm{n}$ a ch der Schwarzerdebildung geschlossen werden kann.

Das Deckschichtenprofil mit den eingeschalteten Böden gliedert sich wie folgt:

\begin{tabular}{lrl} 
A & $0-0,20 \mathrm{~m}$ & $0,20 \mathrm{~m}$ \\
(B) & $-0,50 \mathrm{~m}$ & $0,30 \mathrm{~m}$ \\
C & $-3,30 \mathrm{~m}$ & $2,80 \mathrm{~m}$ \\
\hline A $_{1}$ & $-3,50 \mathrm{~m}$ & $0,20 \mathrm{~m}$
\end{tabular}

A

$-3,85 \mathrm{~m} \quad 0,35 \mathrm{~m}$

$\mathrm{B}_{1}$

$-5,35 \mathrm{~m} \quad 1,50 \mathrm{~m}$

\section{Be}

A$$
\text { C }
$$

C

$$
\text { C }
$$
di (1) wohl auf den geringeren Kalk- bzw. Basengehalt der Fließerde zurückzuführen

graubrauner, humoser Lößlehm, unten etwas heller.

brauner Lößlehm, säulig, vieleckig brechend.

hellgelber Löß, im $\mathrm{N}$ bis $6 \mathrm{~m}$ mächtig.

graubrauner, schwach humoser, feinsandiger Lehm, schichtig-blättrige Struktur; teilweise mächtiger, stellenweise abgetragen, an den Erosionsstellen Kies und Sand.

hellgrauer, gebleichter, feinsandiger und sandiger Lehm, unten grauweiße Bleichflecken.

brauner, feinsandiger und sandiger, geschichteter Lehm, fest verbacken, säulig, vieleckig brechend, auf den Bruchflächen dunkelbraune Überzüge von Eisen-Humus-Gelen.

gelbbrauner, feinsandiger Lehm.

graubrauner, humoser Lößlehm, in feuchtem Zustand schwärzlichbraun.

grauweißer Lößlehm mit Eisenhydroxyd-Konkretionen. brauner Lößlehm, säulig, vieleckig brechend, im mittleren Teil schwarzbraune Humuseinschlämmungen.

gelber Löß, stark kalkhaltig, z. T. mit weißen Kalkbändern. Schwarzerde mit $1-2 \mathrm{~cm}$ starken Lößschmitzen; da-

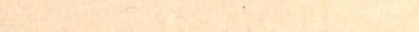




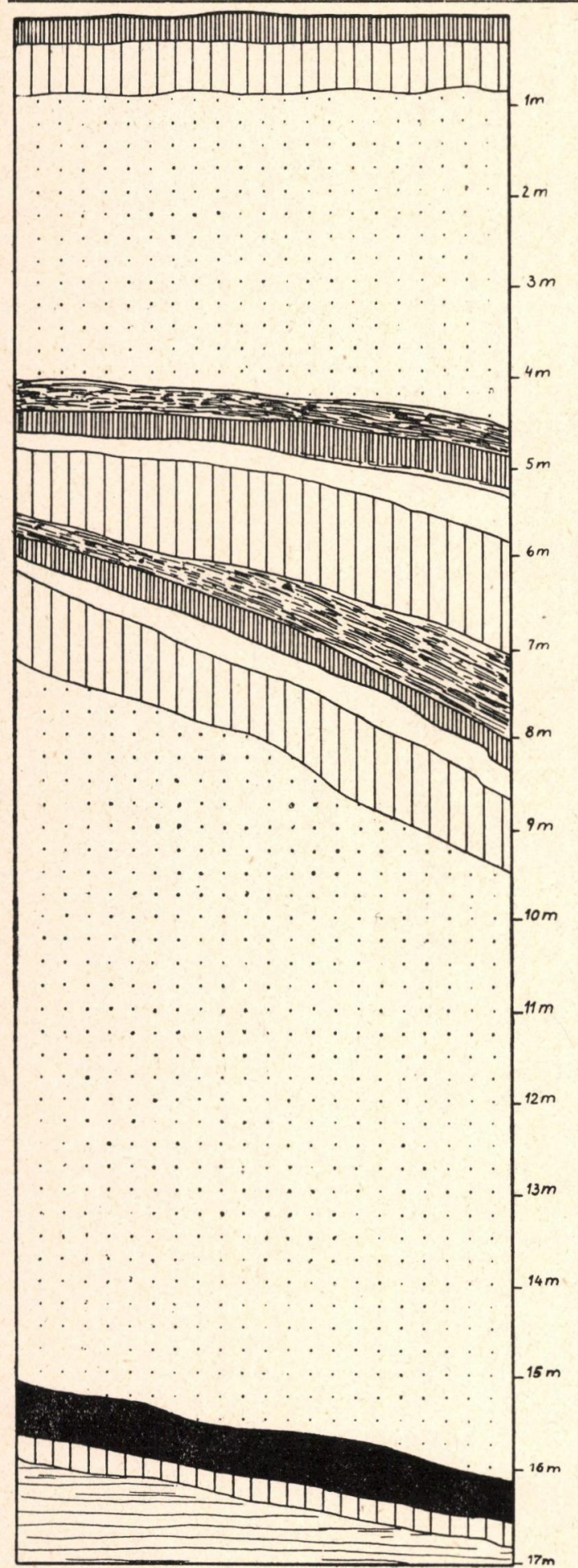

Braunerde

Würm III-Löß

umgelagerter Lehm (Fließerde II)

Würm II-Löß, verlehmt, mit stark podsoliertem Boden d. Würm II/IIIInterstadials; $\mathrm{A}_{1-}, \mathrm{A}_{2}-\mathrm{u}$. B-Horizont

umgelagerter Lehm (Fließerde I)

stark podsolierter Boden d. Würm I/II-Interstadials mit $\mathrm{A}_{1-}, \mathrm{A}_{2-}$ und B-Horizont

\section{Würm I-Löß}

degradierte Schwarzerde d. RißWürm-Interglazials auf Riß-Löß; darunter Pläner

Abb. 7: Löße, Fließerden und fossile Böden in der Ziegelei bei Kropatsch-Wrutitz. 
ist. Ausgeprägte Bleichhorizonte und Anreicherungen von durchgeschlämmten Eisen-Huminsäuregelen im B-Horizont lassen den bereits fortgeschrittenen Podsolierungsgrad erkennen.

Aus den Eisenhydroxydkonkretionen in den unteren $10 \mathrm{~cm}$ des $\mathrm{A}_{2}$-Horizontes des tiefsten Podsolprofils geht hervor, daß der B-Horizont durch zugewanderte kolloidale Substanzen eine Verdichtung erfahren hat, wodurch eine zeitweilige Staunässe verursacht wurde (gleiartig).

Grundsätzlich den gleichen bodenkundlichen Aufbau besitzt das Pleistozänprofil in der Ziegelei westlich Kropatsch-Wrutitz (Bl. Melnik, Sekt. 4; vgl. Abb. 7). Der etwa $16 \mathrm{~m}$ hohe Aufschluß liegt am Nordrand des Struhatals, das in SW-NORichtung das südöstliche Blattgebiet durchzieht. Unmittelbar am westlichen Dorfrand mündet ein kleines von NW kommendes Tälchen, das die zwischen Kropatsch-Wrutitz und Wtelno gelegene etwa $260 \mathrm{~m}$ hohe Lößfläche von der in westlicher Richtung sich anschließenden $245 \mathrm{~m}$ hohen Kreideebene trennt. Am Westrand dieser schon alt angelegten Erosionsrinne blieben verschiedenaltrige Löße erhalten, und zwar kann man über dem festen Kreidepläner 4 Löße unterscheiden, die alle noch ihre vollständige Verwitterungsdecke besitzen. Der tiefste, nur knapp $1 \mathrm{~m}$ mächtige Löß dürfte schon im Riß-Glazial entstanden sein, die darüber folgenden im Würm. Auf dem ältesten Löß ist eine $0,6 \mathrm{~m}$ mächtige entkalkte Schwarzerde ausgebildet, die einen braunen B-Horizont aufweist. Über dem milden, humosen Lehm folgt der 6-9 m mächtige Würm I-Löß mit einem ausgeprägten $\mathrm{P}$ o d s o 1 profil. Der $25 \mathrm{~cm}$ starke humose A-Horizont unterscheidet sich deutlich von dem $15-20 \mathrm{~cm}$ mächtigen grauen $\mathrm{A}_{2}$-Horizont (Bleichhorizont). Der dunkelbraune, etwa $0,8 \mathrm{~m}$ starke B-Horizont ist säulig-vieleckig abgesondert. Auf diesem im Würm I/II-Interstadial entstandenen Podsolprofil wurde ein braun und grau gestreifter Lehm $(25-50 \mathrm{~cm})$ abgelagert, der hangaufwärts schwächer wird. Wahrscheinlich handelt es sich um die am höheren Hang abgetragene Verwitterungsdecke des liegenden Lößes. Die Zuführung des Materials erfolgte $\mathrm{n}$ a $\mathrm{ch}$ der Entstehung des Bodenprofils und vor der Anwehung des hangenden Lößes, also zu Beginn des Würm II-Glazials (Fließerde I). Wie auf dem Würm ILöß, so entstand auch auf diesem Löß im zweiten Würm-Interstadial ein p od s o li e r t e r Boden. Die Podsolierung dieses zweiten Profils ist auch hier stärker als die des tieferen begrabenen Bodens. Dieses unversehrt erhaltene Bodenprofil wurde wie das tiefere von einem graubraunen und braun gebänderten, etwa $30 \mathrm{~cm}$ starken Lehm bedeckt, der wohl ebenfalls als die umgelagerte Verwitterungsdecke des liegenden Lößes anzusehen ist (Fließerde II). Über dem Lehm folgt der bis zu 4,5 m mächtige dritte und jüngste Würm-Löß mit einer typischen Braunerde, wie sie heute nördlich Kropatsch-Wrutitz angetroffen wird.

Betrachten wir diesen Aufschluß noch einmal in seiner Gesamtheit, so stellen wir fest, daß hier nur Ablagerung und Verwitterung aufeinander folgten; Anzeichen einer Abtragung sind nicht vorhanden. Die Verwitterung der beiden mittleren Bodenprofile war intensiv, aber nicht tiefreichend. Das gleiche konnte in der Ziegelei Klima beobachtet werden, wo dem bis $\mathrm{zu} 40 \mathrm{~cm}$ betragenden Bleichhorizont nur ein etwa $1 \mathrm{~m}$ mächtiger B-Horizont entspricht. Vergleicht man hiermit rezente Lößböden mit einem ähnlichen Podsolierungsgrad, so ergibt sich, daß diese um ein Vielfaches tiefer verlehmt bzw. entkalkt sind. Auch schon schwach podsolierte Lößböden haben i. a. wesentlich stärkere B-Horizonte.

Die Unterschiede werden besonders bei einer Gegenüberstellung der fossilen Podsolprofile und der rezenten Braunerde deutlich: dieBraunerde nördlich Wrutitz ist im allgemeinen bis zu einer Tiefe von $1 \mathrm{~m}$ entkalkt, das untere Podsolprofil aber nur $1,3 \mathrm{~m}$ und das obere etwa $1,9 \mathrm{~m}$. 
Weitere fossile Schwarzerden fand ŽEBERA in Nordwestböhmen in der Umgebung von Raudnitz a. d. Elbe. Er weist diese Schwarzerden ebenfalls dem letzten Interglazial zu (briefl. Mitt.).

Böden, die auf Staunässe hinweisen, sind nur von 2 Stellen bekannt geworden. So liegt in der Ziegelei Schultz bei Stěžer ( $5 \mathrm{~km}$ westlich von Königgrätz) unter dem jüngsten Würm-Löß ein begrabener Boden mit einem $50-60 \mathrm{~cm}$ mächtigen grauweißen Ag-Horizont von plattiger Struktur und einem etwa 1,3 m mächtigen stark rost- und graufleckigen Bg-Horizont. Die Rekonstruktion der alten Landoberfläche ergab, daß es sich um eine kleine, flache Mulde handelte, die im Anschluß an die Bodenbildung durch Schwemmlehm und Fließerden wieder zugefüllt wurde. Auf der neu entstandenen ebenen Landoberfläche kam anschließend der Würm III-Löß zur Ablagerung. Aus der Beschaffenheit des fossilen Bodens, insbesondere aus den im Ag-Horizont gleichmäßig verteilten kleinen Konkretionen, kann geschlossen werden, daß der Boden während der längsten Zeit des Jahres vernäßt und nur kurze Zeit trocken war. Die Staunässe ist in erster Linie auf die Muldenlage zurückzuführen. Da sich nun aber die postglaziale Braunerde in ebenem Gelände bildete, kann der fossile gleiartige Boden wegen des Wechsels eines bodenbildenden Hauptfaktors bei der klimatischen Auswertung nicht verwandt werden.

Nur selten sind im mittelböhmischen Bergland die pleistozänen Ablagerungen so gut aufgeschlossen wie in der Ziegelei Steiner bei Beneschau, wo auf den insgesamt $6 \mathrm{~m}$ mächtigen, z. T. aus Lößmaterial bestehenden Gehängelehmen 3 fossile g l e i a r ti g e Böden erhalten sind, während die postglaziale Verwitterungsdecke als Braunerde mittlerer Sättigung ausgebildet ist. Die fossilen gleiartigen Böden ähneln sehr stark den hessischen, jedoch mit dem Unterschied, daß bei Beneschau keine scharf begrenzten basalen Konkretionsbänkchen im Ag-Horizont vorkommen. Immerhin ist auch hier die Aufeinanderfolge von 3 gleiartigen Böden stärkener Ausprägung und der Abschluß des Pleistozänprofils durch eine Braunerde recht bemerkenswert.

Auch aus $\mathrm{M}$ äh re n, das auf größeren Flächen rezente Steppenböden aufweist, sind fossile Schwarzerden bekannt geworden. Genauere Untersuchungen an Profilen aus Mittelmähren führte PELIŠEK $(1938,1939,1940)$ aus. Westlich von Brünn, bei Wischau und im Schwarzawatal fand PELISEK 2 begrabene Schwarzerden, die 3 Lößkomplexe voneinander trennen. Die untere stärker degradierte Schwarzerde mit einem $0,8-1,0 \mathrm{~m}$ starken rostbraunen B-Horizont wird 1-1,5 m mächtig, die obere schwächer degradierte dagegen nur etwa 0,7 m. Als Entstehungszeiten werden von PELISEK zwei Interglaziale angesehen.

Aus der östlichen Wischauer Senke beschreibt STEJSKAL (1941) zwei übereinanderliegende fossile Schwarzerden auf Löß, die ebenfalls degradiert sind und einen braunen B-Horizont aufweisen. - Im Sommer 1943 fand ŽEBERA (1943) in einem Aufschluß bei Brünn 9 verschiedenaltrige Löße mit ihren Verwitterungsdecken. Auch hier gehört die S c h w a r ze rde dem R i $\beta-W$ ü r mInterglazial an, während die beiden Würm-Interstadiale durch Braunerden charakterisiert sind.

In Südmähren beobachtete ZOTZ (1939) im Jahre 1936 in der Ziegelei bei Unter-Wisternitz im oberen Teil des jüngeren Lößes „eine dunkle rötlichbraune Zone“, die über der rostroten „Göttweiger" Verlehmungszone liegt. Auch bei dem Dorf Moravany im unteren Waagtal (Slowakei) kommen im jüngeren Löß Verlehmungszonen von 1 bis 1,5 m Mächtigkeit vor (ZOTZ 1939). 


\section{Weitere Vorkommen fossiler Böden}

Mehrere Schwarzerdevorkommen sind aus Mitteldeutschland bekannt geworden. Bei dem Bau der Eisenbahn Querfurt-Vitzenburg im Jahre 1903 konnte WEISSERMEL (1930) an verschiedenen Stellen begrabene Schwarzerden von 0,5 bis $1 \mathrm{~m}$ Mächtigkeit unter jüngerem Löß feststellen. HOHENSTEIN (1920) erwähnt eine 0,6 bis $1 \mathrm{~m}$ mächtige Schwarzerde von Großengottern zwischen Langensalza und Mühlhausen. Der begrabene Boden liegt unter $4 \mathrm{~m}$ mächtigem Löß und hat einen Humusgehalt von $2 \%$. In dem benachbarten Heroldishausen war unter $5 \mathrm{~m}$ mächtigem Löß eine $0,75-1,0 \mathrm{~m}$ starke Schwarzerde aufgeschlossen. Weitere begrabene Schwarzerden beobachtete HOHENSTEIN zwischen Weißenfels und Zeitz und bei Rottelsdorf im Mansfeldischen. SOERGEL (1924) beschreibt 2 fossile Schwarzerden (degradiert) auf 2 älteren Lößen von Oßmannstedt in Thüringen. In diesem Zusammenhang sei auch das Pleistozänprofil von Wickerstedt erwähnt (SOERGEL 1939); hier liegt auf dem verlehmten Ilm-Auemergel eine Keuper-Fließerde, die eine humose Verwitterungsdecke trägt. Diese bedeckt jedoch nur noch stellenweise die im Riß II-Glazial entstandene Fließerde, war aber, wie aus den mit humosem Material gefüllten Eiskeilen hervorgeht, ehemals auf der gesamten Fließerde vorhanden. Nach den Beobachtungen von SOERGEL möchte ich annehmen, daß es sich bei dieser humosen Verwitterungsdecke, die eine Durchschnittsmächtigkeit von 1,2 m erreicht, um einen Boden von Schwarzerde- oder Rendzinacharakter handelte. Als Bildungszeit nimmt SOERGEL das Riß-Würm-Interglazial an.

Gleiartige Böden beobachtete MÜCKENHAUSEN am Rodder Berg bei Mehlem und bei Muffendorf in der Nähe von Godesberg. An beiden Stellen wird der entkalkte, stark ausgeprägte gleiartige Lößboden von jüngerem kalkhaltigem Löß bedeckt. (Für die Mitteilung dieser Beobachtungen sei Herrn Dozent Dr. MÜCKENHAUSEN bestens gedankt).

III. Boden und Klima während der jungpleistozänen Verwitterungs $\mathrm{z}$ it en

Wir wollen nun abschließend die mitgeteilten Beobachtungen noch einer kurzen vergleichenden Gesamtbetrachtung unterziehen. Von wesentlicher Bedeutung sind natürlich die auf den einzelnen Ablagerungen entwickelten B o d e ntypen und die Verlehmungsti efen. Vergleichen wir zunächst einmal die interglazialen und interstadialen Verwitterungsdecken miteinander, so stellt man erwartungsgemäß beträchtliche Unterschiede fest.

Die Verlehmung der intergla $\mathrm{z}$ i a le n Böden reicht über $3 \mathrm{~m}$ tief, die der inter stadiale $\mathrm{n}$ bleibt meistens unter $2 \mathrm{~m}$. Dabei ist $\mathrm{zu}$ bemerken, daß die in Nordböhmen vorkommenden, weniger als $1 \mathrm{~m}$ betragenden interglazialen Verwitterungstiefen durch die geringe primäre Mächtigkeit des Bodenausgangsgesteins oder durch nachträgliche Erosion bedingt sind. Weniger tiefe Verwitterungen und schwächere Entkalkungen der interglazialen Böden finden sich an verschiedenen Stellen in Rheinhessen, im Rheingau und in Mitteldeutschland. In diesen Gebieten ist die Schwarzerde und ihr brauner Degradationssaum meist noch kalkhaltig, sofern der letztere überhaupt ausgebildet ist. Auch in Nordböhmen erreicht die Degradation mitunter einen schwächeren Grad. Bemerkenswert ist demgegenüber die starke Degradierung der Schwarzerde von Münzenberg und Berstadt in der Wetterau und von Oßmannstedt in Thüringen.

Die Verwitterungsdecken des letzten Interglazials können daher hinsichtlich der Bodenform in die folgenden 3 Gruppen zusammengefaßt werden: 
1. Kalkhaltige Schwarzerden, z. T. mit kalkhaltigem, braunem B-Horizont (schwach degradiert).

2. Entkalkte Schwarzerden mit kalkfreiem, braunem B-Horizont verschiedener Mächtigkeit (mäßig bis stark degradierte Schwarzerden).

3. Stark degradierte bzw. podsolierte Schwarzerden.

Die Schwarzerden der Gruppe 1 sind nach den bisher durchgeführten Untersuchungen auf gewisse Gebiete Rheinhessens, des Rheingaues und Mitteldeutschlands beschränkt, während die mäßig bis stark degradierten im Vortaunus (südliche Wetterau) und vor allem in den böhmisch-mährischen Lößgebieten vorkommen. Die stark degradierten bzw. podsolierten Schwarzerden wurden nur bei Münzenberg und Berstadt in der nördlichen Wetterau sowie bei Oßmannstedt beobachtet.

Die letztinterglazialen Schwarzerden liegen also in etwa denselben Gebieten wie die postglazialen; doch ist $\mathrm{zu}$ bemerken, daß die rezente Schwarzerde in Rheinhessen nur kleinere Flächen einnimmt und im Rheingau nur ganz vereinzelt und auf kleinsten Arealen vorkommt. Hier sind die Braunerde und in Rheinhessen der unentwickelte, helle und humusarme Lößboden die verbreitetsten Bodentypen. $\mathrm{Ob}$ die Schwarzerde während des letzten Interglazials in diesen beiden Gebieten eine größere Ausdehnung besaß, kann auf Grund der z. Zt. bekannten fossilen Vorkommen nicht gesagt werden; im Rheingau und Vortaunus scheint dies jedoch der Fall gewesen zu sein. - Auch die stark degradierten Schwarzerden von Münzenberg und Berstadt liegen in einem Gebiet mit rezenten Schwarzerdevorkommen, die allerdings nicht die auf der Bodenkarte des Deutschen Reiches eingezeichneten großen Flächen einnehmen (STREMME 1936).

Eine größere Ausdehnung als heute scheint die interglaziale Schwarzerde in Nordböhmen gehabt zu haben, denn hier ist beispielsweise in der Gegend südwestlich Jungbunzlau heute die B r a u n e r d e der verbreitetste Bodentyp.

Auch bei den interstadialen Verwitterungsdecken können eine Anzahl Bodentypen unterschieden werden und zwar die folgenden 5 Gruppen:

1. Kalkhaltige, wenig und flach verlehmte Böden; Tonaufbau gehemmt; unentwickelte Böden.

2. Schwach kalkhaltige, tiefer verlehmte Böden (bis $0,8 \mathrm{~m}$ ); nicht voll entwickelte Braunerden.

3. Kalkfreie, tief verlehmte Böden (über $1 \mathrm{~m}$ ); Braunerden.

4. Podsoliertè Böden.

5. Gleiartige Böden.

In der regionalen Verteilung dieser Bodentypen bestehen gewisse Unterschiede. Die erste Gruppe findet sich besonders in Niederhessen, vereinzelt auch im Rhein-Maingebiet; doch ist hier die zweite Gruppe bei weitem die häufigste. Mitunter treten auch in diesem Gebiet bei etwa gleichbleibender Verlehmungstiefe kalkfreie Profile auf, die als Übergangsstadien zur dritten Gruppe aufzufassen sind. Diese hat in den böhmisch-mährischen Lößgebieten ihre Hauptverbreitung. Die Podsolprofile wurden nur in der mittleren böhmischen Elbelandschaft und bei Homberg in Niederhessen beobachtet.

Neben diesen regionalen Unterschieden spielt die bereits skizzierte allgemeine Verteilung der Schwarzerde-Typen eine besondere Rolle, weil aus ihr wichtige Schlüsse hinsichtlich des Klimas gezogen werden können.

Die Schwarzerde gilt allgemein als der das Steppenklima charakterisierende Bodentyp, der sich durch eine Anreicherung echter, mit Basen gesättigter Humusstoffe auszeichnet (vor allem $\mathrm{Ca}$ und $\mathrm{Mg}$ ). Dieser unter geringer Durchfeuch- 
tung gebildete humose Boden mit seinem optimalen Bodenleben verliert, wenn er unter den Einfluß einer stärkeren Durchfeuchtung bzw. einer Waldvegetation gerät, seine günstigen chemisch-biologischen Eigenschaften, was sich an einer Abnahme der Basensättigung und Verbraunung bemerkbar macht. Bei weiterem Absinken der Basensättigung können die sich anhäufenden Humusstoffe auf der an tonigen Bestandteilen armen und ihrer edlen Humussäuren durch mikrobiellen Abbau beraubten Schwarzerde nicht mehr normal zersetzt werden, so daß saure Auflagedecken entstehen. Eine verstärkte Degradation, die unter Umständen recht schnell eintreten und schließlich zur Podsolierung führen kann, ist die Folge.

Nach diesen in den jetzigen Schwarzerdegebieten gewonnenen Erkenntnissen zu urteilen, bestanden daher während des le t z te n In te r g l a zials in Rheinhessen, im Rheingau, im Thüringer Becken und in den Lößgebieten östlich und südöstlich des Harzes bis in die Gegend Zeitz-Weißenfels optimale Bedingungen für die Bildung und Erhaltung der Schwarzerde. Während in diesen Gebieten keine oder nur eine schwache Degradation stattfand, das Klima also im gesamten Interglazial einen mehr oder weniger kontinentalen Charakter behielt, ist in den übrigen Schwarzerdegebieten und in den Randzonen der zuvor genannten Landschaften durchweg eine stärkere Degradation zu verzeichnen, was auf das Vordringen des Waldes während der feuchteren Phase des Interglazials zurückzuführen sein dürfte.

Genau wie heute waren demnach auch im letzten Interglazial $R \mathrm{~h}$ e in h es sen, die zentrale Thüringer Mulde und die Magdeburg-Halle'sche Börde die trockensten deutschen Landschaften. Die hier und in den anderen erwähnten Gebieten erhaltenen fossilen Schwarzerden deuten wegen der schwachen oder fehlenden Degradation sogar darauf hin, daß das Klima des letzten Interglazials günstiger war als das der $\mathrm{Nach}$ eis zeit, was ja auch zahlreiche pollenanalytische Untersuchungen ergeben haben (vgl. die Ausführungen von BÜDEL 1950, S. 439).

Die Verbreitung der interstadialen Bodentypen ist ebenso wie die regionale Verteilung der Schwarzerdetypen des letzten Interglazials klim at is ch bedingt. Wie aus anderen Beobachtungen geschlossen werden kann, war das Klima der Interstadiale kühler und feuchter als das der echten Interglazialzeiten (vgl. WOLDSTEDT 1947), was auch in allen bisher bekannt gewordenen vertikalen Bodentypen-Sukzessionen klar zum Ausdruck kommt. Selbstverständlich wies das Klima der jeweiligen Verwitterungszeiten genau wie heute Unterschiede auf, so daß in der gleichen Verwitterungszeit nichtüberalldieselben Bodentypen entstanden, selbst wenn das Ausgangsmaterial das gleiche war; denn der Bodentyp ist nicht nur vom Gestein, sondern auch von der Vegetation, dem Einfluß des Wassers und der Geländeform abhängig. Es entstanden daher zur gleichen Zeit voneinander abweichende Bodentypen, wie an dem Wechsel der interstadialen Bodentypen zu erkennen ist, z. B. im Rheingau Braunerden, im Usinger Becken und am Rand des Vogelsbergs gleiartige Böden, in Nordhessen Braunerden, in Nordböhmen Podsole und Braunerden. Aus diesem Grunde ist es auch nicht möglich, ein und derselben $\mathrm{Z}$ eit nur einen bestimmten Bodentypzuzuweisen.

Wenn in der vorliegenden Untersuchung aus dem letzten Interglazial nur Schwarzerden und ihre Degradationsformen erwähnt werden, so darf dadurch nicht der Eindruck entstehen, daß das letzte Interglazial ganz allgemein durch Schwarzerden charakterisiert sei (vgl. BÜDEL 1950, S. 447, Anm. 2). Es wurden 
ja bisher lediglich die i. a. tiefer liegenden und trockeneren Lößgebiete untersucht, so daß von vorneherein auch für das letzte Interglazial andere Bodentypen kaum zu erwarten waren. In den feuchteren und meist höher gelegenen Randgebieten, wo die Erhaltungsbedingungen allerdings ungünstiger waren, werden im Interglazial aller Wahrscheinlichkeit nach keine Schwarzerden, sondern weniger humose, basenärmere und z. T. auch podsolierte oder gleiartige Böden entstanden sein.

Um den erdgeschichtlichen Klimaverlauf eines bestimmten Ortes aufzeigen zu können, darf nur von der vertikalen Bodentypensukzession ausgegangen werden, wobei die jeweils wirksam gewesenen bodenbildenden Faktoren zu berücksichtigen sind. Nur die unter gleichen oder ähnlichen Bedingungen entstandenen gleichaltrigen Bodentypen können zu einer regionalen klimatischen Auswertung herangezogen werden, was am besten an Hand von Bodenkarten der einzelnen Verwitterungszeiten erreicht wird. An diese Aufgabe kann jedoch erst herangegangen werden, wenn genügend Untersuchungsergebnisse vorliegen.

\section{Zus a m m enf assung}

Die Untersuchung fossiler Böden in einigen Landschaften des eisfreien Gebietes hat ergeben, daß die verschiedenen Verwitterungszeiten des jüngeren Pleistozäns durch bestimmte Bodentypen charakterisiert sind. So bildeten sich während des Riß-W ürm-Interglazials im engeren Rhein-Maingebiet, in Mitteldeutschland, in Nordböhmen und Mähren Sch wa rzerden, die in folgende Bodenformen unterteilt werden können:

1. Kalkhaltige Schwarzerden mit normalen A/C-Profilen.

2. Degradierte Schwarzerden mit A/B/C-Profilen.

3. Podsolierte Schwarzerden mit $\mathrm{A}_{1} / \mathrm{A}_{2} / \mathrm{B} / \mathrm{C}-$ Profilen.

Die regionale Verteilung dieser Typen und die daraus abzuleitenden allgemeinen Klimaverhältnisse werden erläutert.

Während der Würm-Interstadialzeiten entstanden folgende Bodentypen:

1. Kalkhaltige, wenig und flach verlehmte Böden; unentwickelte Böden.

2. Schwach kalkhaltige, stärker und tiefer verlehmte Böden (bis $0,8 \mathrm{~m}$ ); nicht voll entwickelte Braunerden.

3. Kalkfreie, über $1 \mathrm{~m}$ tief verlehmte Böden; Braunerden.

4. Podsolierte und

5. Gleiartige Böden.

In der Verbreitung dieser Bodentypen lassen sich bestimmte Unterschiede feststellen, die ebenfalls auf die Einwirkungen des Klimas zurückgeführt werden.

Die Untersuchungen haben gezeigt, daß es möglich ist, mit Hilfe der Bodentypen-Sukzessionen den Klimaverlauf der betreffenden Gebiete während des jüngeren Pleistozäns in seinen Grundzügen zu erfassen. Hiermit erlangen die fossilen Böden für die gesamte Eiszeitforschung und die Paläoklimatologie eine erhöhte Bedeutung, weshalb sie besondere Aufmerksamkeit verdienen. Um jedoch Bodenkarten der einzelnen Verwitterungszeiten entwerfen zu können, die die beste Grundlage für eine regionale klimatische Auswertung darstellen, sind noch weitere Beobachtungen in den behandelten und in den übrigen Gebieten notwendig, wozu diese Arbeit einige Anregungen geben möchte. 
Anmerkung: In der anschließenden Diskussion machte Herr Dr. MƯCKENHAUSEN (Geol. Landesamt für Nordrhein-Westfalen, Krefeld) auf die Schwierigkeiten bei der Ansprache des Bodentyps fossiler Verwitterungsdecken aufmerksam. So könne beispielsweise von dem bodenkundlich weniger geschulten Beobachter ein verschwemmter Lößlehm leicht mit einer braunen Verlehmungszone verwechselt werden; nicht jeder dunkle Boden sei eine Schwarzerde. Bei der Bestimmung des Karbonatgehalts müsse man Vorsicht walten lassen, denn der Kalkgehalt könne auch aus hangenden Lößen zugewandert sein.

\section{Schriftenverzeichnis}

BÜDEL, J.: Die Klimaphasen der Würmeiszeit.-Naturwissensch. 37, S. 438-449, Berlin, Göttingen, Heidelberg 1950.

GERTH, H.: Über die Gliederung des Lößes auf den Terrassen am Taunusrand zwischen Höchst und Wiesbaden. - Ber. Vers, niederrhein. geol. Ver. Jg. 1909, S. $45-49$, Bonn 1909.

HARRASSOWITZ, H.: Fossile Verwitterungsdecken. - Handbuch der Bodenlehre 4, S. 225-305, Berlin 1930.

HESS, W.: Über die vulkanische Asche im Diluvium des Limburger Beckens. - Ber. Vers. niederrhein. geol. Ver. Jg. 1909, S. 8-9, Bonn 1909.

HOHENSTEIN, V.: Die Löß- und Schwarzerdeböden Rheinhessens. - Jber. u. Mitt. oberrhein. geol. Ver. N. F. 9, S. 74-97, Stuttgart 1920.

MEYER, H. L. F. (HARRASSOWITZ): Einige Lößprofile der Wetterau. - Ber. oberhess. Ges. Nat. und Heilkde. N. F. 3, S. 88-94, Gießen 1910.

MICHELS, FR.: Erl. geol. K. v. Preußen und benachbarten deutschen Ländern 1:25 000, Bl. Eltville-Heidenfahrt, 79 S., Berlin 1931.

MORDZIOL: C.: Über den Nachweis von älterem Löß bei Wiesbaden. - Jb. Nass. Ver. Naturk. 63, S. 257-262, Wiesbaden 1910.

PELIŠEK, J.: Příspěvek $\mathrm{k}$ studiụ diluviálních půd ve stredomoravských spraších. (Ein Beitrag zum Studium der Diluvialböden in mährischen Lößen). — Práce Moravské přírodovědecké společnosti 11, F. 106, Brünn 1938.

PELIŠEK, J.: Diluviální nory („krotoviny“) v pohřbených černozemích od Vyškova na Moravě. (Diluviale "Krotowinen" in den begrabenen Schwarzerden von Mähren). - Příroda 32, Brünn 1939.

PELIŠEK, J.: Cernozemé pohřbené (diluviální) ve spraších od Vyškova. (Begrabene diluviale Schwarzerden in den Lößen von Wischau, Mähren). - Sborník Klubu prŕírodovědeckého $\mathrm{v}$ Brně 22, Brünn 1940.

PELIŠEK, J.: Studie diluviálních půd (ve spraších) a diluviálního podnebi v oblasti svnateckého úvalu na Moravě. (Studie über die diluvialen Böden in Lößen und das diluviale Klima im Gebiet des Schwarzawatals in Mähren). Práce Moravské př́rodovědecké společnosti 12, F. 112, Brünn 1940.

SCHNELL, A.: Chemische Untersuchungen über den Löß von Sprendlingen (Rheinhessen). - Diss., Gießen 1928.

SCHONHALS, E.: Ubber verschiedenaltrige Löße und ihre fossilen Verwitterungsdekken bei Homberg a. d. Efze (Bez. Kassel). - Ber. Reichsamt Bodenforschung, Jg. 1944, S. 111-119, Wien 1945.

SCHÖNHALS, E.: Ủber einige wichtige Lößprofile und begrabene Böden im Rheingau. - Notizbl. hess. L. Amt Bodenforsch. VI. F., S. 244-259, Wiesbaden 1950.

SCHONHALS, E.: Fossile gleiartige Böden des Pleistozäns im Usinger Becken und am Rand des Vogelsbergs. - Notizbl. hess. L.-Amt Bodenforsch. VI. F., S. 160 bis 183; 4 Taf., Wiesbaden 1951.

SELZER, G.: Diluviale Lößkeile und Lößkeilnetze aus der Umgebung Göttingens. Geol. Rdsch. 27, S. 275-293, Stuttgart 1936.

SNAJDR, L.: Die vorgeschichtlichen Denkmäler menschlicher Tätigkeit im böhmischen Elbetal. - Pravěk 5, Kojetein i. d. Hanna 1909.

SOERGEL, W.: Die diluvialen Terrassen der Ilm und ihre Bedeutung für die Gliederung des Eiszeitalters. - 78 S., 6 Taf., Jena 1924.

SOERGEL, W.: Die geologischen Grundlagen der Vollgliederung des Eiszeitalters. Fortschr. Geol. Pal. 12, H. 39, 292 S., Berlin 1939.

STEJSKAL, J.: Pokryvné útvary ve východni části vyškovského uvalu. Mit deutscher Zusammenfassung: Bedeckungsablagerungen im östlichen Teil der Wischauer Senke. - Mitt. Amt Bodenf. Böhmen und Mähnen 17, S. 158-165 „Prag 1941.

STREMME, H.: Die Böden des Deutschen Reiches und der Freien Stadt Danzig. Petermanns Mitt. Erg. H. 226, 74 S., 14 Taf., Gotha 1936. 
WEISSERMEL, W.: Zur Stratigraphie und Tektonik des östlichen Teils der subherzynen Mulde und ihrer nordöstlichen Nachbargebiete. - Abh. pr. geol. L. A. N. F. H. 125, 93 S., 4 Taf., Berlin 1930.

WOLDSTEDT, P.: Die Strahlungskurve von Milankovitch und die Zahl der Eis- und Zwischeneiszeiten. - Geol. Rdsch. 35, S. 23-25, Stuttgart 1947.

Z.ARUBA-PFEFFERMANN, Q.: Längsprofil durch die Moldauterrassen zwischen Kamaik und Weltrus. - Mitt. Tschech. Akad.Wiss. Jg.52, Nr. 9, S.1-36, Prag 1942.

ZARUBA-PFEFFERMANN, Q.: Periglaziale Erscheinungen in der Umgebung von Prag. - Mitt. Tschech. Akad. Wiss. Jg. 53, Nr. 15, S. 1-33, Prag 1943.

ZEBERA, K.: Devět sprašových pokryvů fosilními půdními s typy pod "Novou horou" na líšenském katastru u Brna. (Neun Lößdecken mit ihren fossilen Bodentypen am Abhang des "Neuen Berg“ in der Gemarkung Lösch bei Brünn). Přiroda 36, Brünn 1943.

ZOTZ, L. F. \& VLK, W.: Das Paläolithikum des unteren Waagtales. - Quartär 2, S. 65-101, Berlin 1939.

ZOTZ, L. F.: Wiederauflebende Urgeschichtsforschung im fränkischen Jura. - Kosmos 44 , S. $54-58$, Stuttgart 1948 .

\section{Die stratigraphische Bewertung periglazialer Umlagerungen im nördlichen Niedersachsen}

\section{Von Konrad R i ch te r, Hannover, Amt für Bodenforschung. Mit $5 \mathrm{Abb}$.}

In der norddeutschen, morphologisch sehr mannigfaltigen Jungmoränenlandschaft liegen die Sedimente der letzten Eiszeit im allgemeinen noch ziemlich unverändert am ursprünglichen Ablagerungsort. Das Altmoränengebiet muß früher ein ähnlich bewegtes Relief gehabt haben. Heute ist es sehr stark eingeebnet. GRIPP wies besonders darauf hin. Es wären daher im nördlichen Niedersachsen eine große Menge von Umlagerungssedimenten zu erwarten, sozusagen eine Landschaft, die im Schutt ertrunken ist. Wir müßten auch zu derselben Auffassung kommen, wenn wir uns aus dem mitteldeutschen, beziehungsweise süddeutschen nicht vereist gewesenen Gebiet in die norddeutsche Altmoränenlandschaft begeben, denn im nicht vereist gewesenen Gebiet liegt nach den Untersuchungen von BÜDEL, GALLWITZ, KESSLER, SOERGEL, K. SCHMID, TROLL und vielen anderen eine Menge periglazialer Ablagerungen, oft nach Art von Pseudomoränen vor, die Ähnliches im Altmoränengebiet erwarten ließen. Auf den geologischen Spezialkarten 1:25000 des Altmoränengebietes im nördlichen Niedersachsen, etwa auf den Blättern um Bremen, ist nichts dergleichen eingetragen. Wir fragen uns: sind wirklich außer den Talsanden und holozänen Sedimenten keine älteren Umlagerungen vorhanden?

DEWERS (1941) schreibt zu dieser Frage sehr kraß: „Ganz allgemein kann gesagt werden, daß am Fuße von Hängen, wo man eigentlich eine Anhäufung von Fließerden vorfinden müßte, meist unter einer dünnen, durch die Pflanzenwurzeln entschichteten Decke sofort geschichtete Bildungen anstehen. Zum mindesten müssen also die anderen Transportmittel, fließendes Wasser und Wind, zur restlosen Entfernung aller Fließerdeanhäufungen ausgereicht haben." An anderen Stellen derselben Arbeit finden sich indes auch zahlreiche Hinweise auf periglaziale Umlagerungen. Die sehr negative Stellungnahme von DEWERS ist aus der mitteldeutschen Perspektive überraschend, und wir fragen: sind vielleicht manche Periglazialsedimente so schwer indentifizierbar, daß sie bisher nicht als solche erkannt wurden? Immerhin haben alle bisher im Altmoränengebiet kartierenden Geologen übereinstimmend berichtet, daß die Abgrenzung z. B. der 